\title{
GPS monitoring of a steel box girder viaduct
}

\author{
Oluropo Ogundipe ${ }^{1}$, GethinW.Roberts ${ }^{1}$, and Christopher J.Brown ${ }^{2} *$ \\ 1 The Institute of Engineering Surveying and Space Geodesy (IESSG), University of Nottingham, \\ NG8 2TU, UK \\ 2 School of Engineering and Design, Brunel University, Uxbridge, UB8 3PH, UK
}

* Author to receive correspondence. Email: chris.brown@brunel.ac.uk

Other Authors Emails: Oluropo.Ogundipe@nottingham.ac.uk \&

Gethin.ROBERTS@,nottingham.edu.cn

\begin{abstract}
Structural performance monitoring of bridges has increased as major infrastructure ages and is required to sustain loads that are significantly greater than those predicted during design. Structural stiffness and/or mass distribution can change over the lifespan of a bridge structure. Resulting changes in profile or resonant frequency provide key indicators of change, and may identify structural defects. Field tests using GPS for monitoring relatively small deformations were carried out on a steel box girder viaduct bridge in the UK. The configuration consisted of five GPS receivers located at key locations on the viaduct and two reference GPS receivers. GPS data was collected at either $10 \mathrm{~Hz}$ or $20 \mathrm{~Hz}$ and post processed using proprietary software, along with appropriate filtering and spectral analysis. Three main frequencies were clearly detected by the GPS in the vertical component. A previously reported frequency of approximately $0.56 \mathrm{~Hz}$ was identified along with two other frequencies. The peak vertical deflections lie in the range of $\pm 50 \mathrm{~mm}$, while lateral and longitudinal deflections of much smaller magnitude - in the order of a few $\mathrm{mm}$ - are also measured. The use of GPS leads to readily obtained and useful engineering data for continued monitoring of structures.
\end{abstract}

Keywords: Structural health monitoring, structural dynamics, digital signal processing, engineering surveying, GPS. 


\section{INTRODUCTION}

This paper aims to demonstrate that GPS can be used to provide data for use in the experimental assessment of existing structures. A study of structural health monitoring (Farrar et al., 2001) defines damage in terms of recognizable changes in system characteristics that affect performance, and implying the need to establish current state in order to measure change. Such change could alter the stiffness, mass, or energy dissipation properties of a system, which in turn would alter the measured dynamic response of the system. The measurement of the frequencies of vibration of a bridge is therefore potentially very important in civil engineering, particularly in critical infrastructure projects. Knowledge of the lower frequencies of vibration can, on a new bridge serve as useful parameters for comparison with those predicted by the numerical models used in design, and give increased confidence in design predictions. Measurement of the bridge frequencies can assist the processes of maintenance and, where necessary, repair. When monitored over a long period, a useful datum for evaluating the degradation in stiffness or strength of the structure is established, and may even lead to possible damage identification in the structure, for example, due to long-term overloading and impacts by heavy vehicles, or sudden extreme events such as earthquakes or tremors (Yang et al., 2004; Yang and Chang, 2009; Sohn et al., 2003). Cunha and Caetano (2006) provide an excellent overview of experimental modal analysis of civil engineering structures (sic) and point out the inherent advantages and disadvantages of output-only methods (Cunha et al., 2007).

Zhou et al. (2010) suggest the concept of a "global response signature" as a basis for condition monitoring, as this signature would contain embedded data, and changes to it would, in theory, imply damage to the structure. Numerous Vibration-Based Damage Detection (VBDD) indices have been proposed (Doebling et al., 1996; Sohn et al., 2003; Salawu, 1997), including those that rely on changes to the eigen-parameters. Zhou et al. (2010), showed that even for fairly stiff structures, VBDD methods might be effective at detecting damage using data from a small number of accelerometers sensors, but in such cases the placement of this instrumentation can be critical.

Measurement is not a trivial issue (Farrar et al., 2001) and intrinsic problems may inhibit structural health monitoring. Various factors such as number and location of sensors, (e.g., Lynch and Loh, 2006)

can be critical, while environmental and operational variations, and changing loading conditions may affect the dynamic response of the structures. These changes can often mask subtler structural changes caused by degradation or damage (Sohn et al., 2003), and may prevent useful information from being obtained, notwithstanding the post-processing of results, for monitoring and feature extraction using 
neural networks, genetic algorithms and other forms of statistical discrimination techniques (Farrar et al., 1999; Farrar and Worden, 2007) that can be an essential part of structural health monitoring. Frangopol et al. (2008) provide a recent publication on the application of such techniques, and in particular the actions structural engineers might adopt in corrective action for structural systems, while several EUfunded projects (e.g., BRIME) have examined the application of a range of techniques to structural health monitoring.

Many sensors such as accelerometers, tilt meters, strain gauges, and (laser) optical devices have historically been used to measure the system response of structures such as bridges and viaducts, but the use of GPS to monitor such characteristics of bridges has now been an ongoing research focus at the University of Nottingham and Brunel University (Ashkenazi et al., 1996; 1997), for a considerable period, although to date it has mainly been applied on suspension bridges whose movements are in the decimetre to metre range, such as the Humber (Brown et al., 1999) and Forth Road Bridges (Roberts et al., 2006a; 2011), as well as the London Millennium Bridge that saw magnitudes in the order of centimetres (Roberts et al., 2006b). On large structures it may be possible to employ more commonlyused technology (such as laser-based instruments) to obtain similar precision, but signals may have to be taken back to a static base station via use of reflector devices or the like; this can be a hazardous and awkward process. The very layout of large bridges makes the measurement of deformations challenging, and attempts to use other methods have proved difficult where large distances have been involved (e.g., the use of optics on the Humber Bridge (Zasso et al.,1993)). GPS overcomes several of these issues in one go. It gives global three-dimensional position at precise times, and at rates of up to $100 \mathrm{~Hz}$. Obtaining deformation was the primary aim, but because of the precise time measurement element, frequencies are also measured implicitly.

Applications of GPS to monitor structures have met with varying degrees of success. An early study by Lovse et al. (1995) demonstrated some of the difficulties, many of which were replicated in the work of Brownjohn (2005). The objective of applied GPS monitoring has differed in other cases (e.g., Xu et al., 1997; Kashima et al., 2001). Nevertheless, there has been a significant increase in the interest in work being carried out using GPS to monitor bridges. Wang et al. (2008) have used a GPS-based system for monitoring the Nanpu cable-stayed bridge in Shanghai, while similar shorter-term campaigns to those of the authors have been carried out elsewhere on major long-span or slender structures (Xu et al., 2001; Leach et al., 1993; Nickitopolou et al., 2006; Psimoulis et al., 2008a; 2008b; Celebi and Sanli, 2002). There have also been attempts to use single frequency receivers (e.g., Saeki and Hori, 2006; Saeki, 2008) to lower costs. However, the use of single frequency receivers requires a longer period to 
resolve the GPS carrier phase integer ambiguity at the start of the session or after a cycle slip. This can be in the order of several minutes compared to a few seconds for dual frequency receivers. In addition if a long baseline is being used, the ionospheric free combination of the L1 and L2 (the frequencies used by GPS (Leick, 2004)) is not available for use in mitigating the ionospheric errors.

Roberts et al. (2011) have shown the generic strengths of GPS, and demonstrated that with the use of dual frequency receivers and an appropriate post-processing data strategy, useful engineering data can be obtained. In particular the changes in "mass" have been identified when traffic flows have increased; significant changes in stiffness have thankfully never occurred during any of the reported trials, although changes in profile as a result of temperature variation are easily detected (Roberts et al., 2010).

This paper investigates the use of GPS receivers in measuring the system response of the Avonmouth Viaduct and the nature of its dynamic deformations. GPS -unlike other sensors- is readily able to provide three-dimensional absolute position information at a rate of $20 \mathrm{~Hz}$, and higher rates if necessary (Roberts et al., 2011). This enables the analysis of the frequency response and, by using multiple receivers in strategic locations, the dynamics of the vertical profile.

The Avonmouth Viaduct in the UK is a 1400m long, twenty (unequal) span twin steel box structure carrying the M5 motorway over the River Avon and neighbouring industrial and residential areas. The bridge was opened to traffic in December 1974. In 2001 strengthening and widening works were completed to bring the bridge to the standard required for 40/44 tonnes vehicles and to increase the number of lanes in each direction from three to four. Unusually for a steel bridge, a localised prestressing system was provided over the river piers as part of the strengthening works. In order to make this system effective in reducing permanent load effects a propping system was installed to support the main span prior to stressing. When the system was removed it was intended that the longitudinal profile of the structure would revert to its original shape. However, localised water accumulation (ponding) during wet weather suggests that this may not be the case. As a result the GPS monitoring feasibility trial was commissioned in order to measure the actual dynamic vertical profile. Real time monitoring of the deck profile was used to help to identify the nature of the deformations and aid with the development of possible solutions. In addition, actual deformation and movement of the bridge with the predicted movements from an FE could be compared, giving confidence in the validity of results produced.

The authors should therefore make clear that this structure has not been assessed because any structural defects had been suspected, but that these data are available as a result of a profile survey commissioned for purposes described above. 


\section{METHODS}

A two-day assessment using GPS was carried out on the Avonmouth Viaduct main span (length 173.7m, see Figure 1) and the adjacent spans on the 29th and 30th of November 2007. Five GPS dual frequency receivers using choke ring antennas were placed at pre-determined locations upon the bridge, and two reference stations were used. The data was all post processed in an on-the-fly manner, before converting it into bridge coordinates and subsequent analysis. Selected results from the trial are presented, and conclusions drawn about the wider application of the process.

Figure 1a: Profile view of viaduct main river span

Figure 1b: Plan showing viaduct direction and GPS antenna locations

Five GPS receivers were attached to the railings on the main span of the bridge (see Figure 1b) for pre-set durations at different times of the day. Point $M$ corresponds to the midpoint of the main river span on the upstream outer rail of the cycle track while point $\mathrm{D}$ is at the midpoint on the inner rail. Points $\mathrm{A}$ and $\mathrm{B}$ are approximately 40m away from either side of point $\mathrm{M}$ and point $\mathrm{C}$ is approximately $50 \mathrm{~m}$ on the other side of the support at pier 9. Figure 2 shows how the antennas were attached to the bridge. Use of the handrail is not an ideal attachment point, but for shorter-term campaigns is appropriate; it is unlikely that significant vertical movement will ensue, and simple calculations

demonstrate that any frequencies of vibration associated with the handrail will be order of magnitude higher than structural values.

Figure 2 : GPS antenna set up showing clamp and tribrach attachment

In line with good practice, two GPS reference stations were set up away from the main body of the bridge. The main reference station was set up at the nearby Bristol Port Company site in the dock area. This was a secure site where the GPS receiver could be left unattended for extended periods of time. The secondary reference was set up on the top of a disused granary building in the dock compound, at approximately the same elevation as the viaduct. This second reference receiver served as a backup, in case of any data loss from the main reference receiver. It also served to validate results obtained from 
the main reference station. The granary site was not used as the main reference station as the building could be subject to slight thermal movements during the day.

A combination of Leica System 500 and System 1200 receivers were used for the trial, both at the reference stations and on the viaduct. The system 1200 receivers are able to collect data at a maximum rate of $20 \mathrm{~Hz}$ while the System 500 receivers are able to collect data at a maximum rate of $10 \mathrm{~Hz}$. The main reference station (Ground_Ref) at the harbour was a System 500 receiver collecting data at $10 \mathrm{~Hz}$ while that at the granary (Granary_Ref) was a system 1200 receiver collecting data at $20 \mathrm{~Hz}$.

\section{Bridge Coordinate System}

The data collected were post-processed using proprietary software. This produced an epoch-by-epoch solution in the GPS WGS84 (ETRF89) coordinate system, which was then converted to Ordnance Survey (OS) British National Grid Coordinates using the software Grid Inquest. For engineering purposes, and to help visualise the positions on the viaduct, the Eastings and Northings were then converted to a local coordinate system or the Bridge Coordinate System (BCS) for which the lateral axis is across the width of the bridge and for which the longitudinal axis is parallel with the major dimension of the bridge (see Figure $1 \mathrm{~b}$ ). The azimuth of the viaduct, $\theta=35^{\circ} 8^{\prime} 54^{\prime \prime}$, can be calculated from the data.

\section{RESULTS}

\section{Deflections}

Bridge movements need to be identified and differentiated from variations caused by changes in the satellite constellation, the effect of the troposphere, and to eliminate errors from sources such as multipath. The effect of the troposphere has been mitigated to a large extent by using a short base-line of 1-2 $\mathrm{km}$ between the reference and the receivers on the bridge. For distances less than $10 \mathrm{~km}$ the effects from the troposphere at the reference and rover sites are correlated and by using the differential algorithm any significant error is removed (Hofmann-Wellenhof et al., 2001).

Relative tropospheric error can also occur where there is a large difference in height between the base and the rover receivers or where there is a difference in the local microclimate leading to uncorrelated errors (Meng, 2002). The main reference (Ground_Ref) used to process the data was at a height of $8 \mathrm{~m}$ above the UK Ordnance Survey Newlyn datum while the points on the bridge had an average height of $42 \mathrm{~m}$. This gives a height difference of $34 \mathrm{~m}$. This height difference along with the 
short baseline length means that any relative troposphere effect would be negligible. According to King and Edwards (2004) the effect of relative tropospheric error starts to have an impact on data from baselines over $30 \mathrm{~km}$ and height differences of over $100 \mathrm{~m}$. Bridges such as the Humber Bridge (UK) where the height difference between the tower and deck is $156 \mathrm{~m}$ or the Akashi Kaikyo (Japan) at 283m would have to take this into consideration. The secondary reference station used at Avonmouth provided a further check on any relative tropospheric delay effects. The second reference (Granary_Ref) was at a height of $69 \mathrm{~m}$ which is $27 \mathrm{~m}$ above the receivers on the viaduct.

Multipath is still one of the major sources of error in GPS surveying. Choke ring antennas were used on both at the reference and bridge locations in order to mitigate some of the effect of multipath (Ogundipe and Roberts, 2011). The System 1200 receivers used also implements their SmartTrack technology on the hardware side. This is patented technology which uses discrete elliptical filters enabling a strong signal with low noise and multipath mitigation (Leica, 2004). Further multipath mitigation can also be implemented for bridge monitoring using adaptive filtering techniques (Meng, 2002).

The typical range of movements of the viaduct is consistently small (as shown in Figures 3 to 6). The dataset for position M (see Figure 3) is shown along with all the other receivers. The data for receivers $\mathrm{A}, \mathrm{M}$ and $\mathrm{C}$ have been offset by $+0.100 \mathrm{~m},+0.050 \mathrm{~m}$ and $-0.050 \mathrm{~m}$ respectively for presentation purposes, while Figure 4 presents a two minute segment of the unfiltered data collected at the midpoint on day 1 in which the cyclic nature of the structural response is evident. It is also clear that some synthesis of this data is needed to make it meaningful.

Figure 3: Vertical deflection of points along profile on Day 2

Figure 4: Unfiltered vertical deflections of Midpoint receiver - 2 minute extract

The data at position M (mid-span) was filtered using a simple moving average filter over a 10 second period (Eq. 1). This equates to 100 points at the data rate of $10 \mathrm{~Hz}$.

$$
\mathrm{D}[\mathrm{i}]=\left(\frac{1}{\mathrm{n}}\right) \times \sum_{\mathrm{i}-\mathrm{n}}^{\mathrm{i}} \mathrm{x}(\mathrm{i})
$$

where $\mathrm{D}[\mathrm{i}]$ is the lateral, longitudinal or vertical deflection at epoch $i$ and $n$ is the size of the moving average window. 
Figure 5: Deflections of Midpoint receiver on Day 1 from 14:30 - 17:00

Figure 6: Deflections of Midpoint receiver on Day 2 from $\sim$ 07:35 - 15:05

The filtered deflections are generally significantly less than $+/-20 \mathrm{~mm}$ (relative to the bridge coordinate system) of the midpoint receiver about the vertical, lateral and longitudinal axes for approximately two and a half hours on Day 1 () and seven and a half hours on Day 2, as illustrated in Figures 5 and 6, respectively.

\section{Vibrations}

A Fast Fourier Transform (FFT) was applied to the data and the resulting spectral analysis on the unfiltered $(10 \mathrm{~Hz}$ data rate) deflections at midpoint on day 1 (see Figure 7) shows that a number of significant frequencies were detected in the vertical direction, but not in the lateral or longitudinal; this is as expected. Peaks representing frequencies of less than $0.05 \mathrm{~Hz}$ are not considered as these represent low frequency multipath effects or longer term effects (Atkins, 2006).

Figure 7: Amplitude spectrum for Midpoint 1 vertical deflection

\section{Vertical Component}

The frequencies identified at Midpoint on day 1 (and their corresponding time period) in order of their strength from the strongest to the weakest are $0.061 \mathrm{~Hz}(16.39 \mathrm{~s}), 0.526 \mathrm{~Hz}(1.90 \mathrm{~s})$ and $1.139 \mathrm{~Hz}(0.88 \mathrm{~s})$. The two frequencies of $0.526 \mathrm{~Hz}$ and $1.139 \mathrm{~Hz}$ are within the expected range for this type of structure. However, the signal at a lower frequency with a higher period of about 16 seconds is not within the expected dynamics for the bridge and is very likely to be due to multipath. For the antenna located on the bridge structure there are two types of multipath that will be experienced. One will be characterised as a low frequency fluctuation due to reflections from stationary objects in the antenna environment. As the satellites move, their elevation angle and thus satellite-reflector-antenna geometry changes, leading to the fluctuations in the multipath characteristics. This is repeated with about a 4 minutes advance daily as the GPS satellites have an orbital period of $11 \mathrm{~h} \mathrm{58min.} \mathrm{The} \mathrm{other} \mathrm{type} \mathrm{of} \mathrm{multipath} \mathrm{is} \mathrm{a} \mathrm{high}$ frequency multipath with a period of sub-minute to $2-3$ minutes. This is caused by mobile or dynamic 
reflecting surfaces in the antenna environment, resulting in randomization of the multipath effects (Ogaja and Satirapod, 2007).

The key frequencies identified for other locations for the vertical deflection are shown in Table 1, in which the key frequencies are colour-coded in order to show possible relationships.

Table 1: Summary of results for the vertical deflections

\section{Lateral and Longitudinal Deflection Component}

Spectral analysis of the horizontal deflections recorded on the viaduct was also performed. Figures 8 and 9 show the results of the lateral and longitudinal deflections at Midpoint on Day 2. The frequencies identified in the lateral deflections are summarised in Table 2. There are no identifiable frequencies in the longitudinal deflections.

Table 2: Summary of results for the lateral deflections

Figure 8: Spectral analysis on the lateral deflections at Midpoint on Day 2

Figure 9: Spectral analysis on the longitudinal deflections at Midpoint on Day 2

\section{Twisting component - rotation about the longitudinal bridge axis}

Positions C and D (see Figure 1) were occupied only on Day 2. Using the data collected at these points along with the data from position $\mathrm{M}$, twisting about the longitudinal axis of the viaduct was computed. The vertical deflection data from position D at the Midpoint, on the inner rail of the cycle track was subtracted from that of position $\mathrm{M}$ on the outer rail to assess twisting movements as shown in Figure 10. Although ideally one other point would be located on the downstream side of the viaduct, access was not possible on the days of the test. Spectral analysis was performed on the twisting data, but there are no clearly identifiable frequencies as it can observed in Figure 11.

Figure 10: Lateral torsional deflection on Day 2

Figure 11: Amplitude spectrum of lateral torsion deflection 


\section{Analysis of $20 \mathrm{~Hz}$ data at midspan}

One of the challenges of monitoring large civil engineering structures such as bridges is that the low sensitivity of frequency shifts to damage requires either very precise measurements of frequency change or large levels of damage. Generally, changes in frequencies alone cannot provide spatial information about damage. The exception to this occurs at higher modal frequencies, where the modes may be associated with local responses (Farrar et al., 1999). Measurements of higher modes are generally subject to lower signal-to-noise ratios, since modal amplitudes tend to diminish with higher modes, but Zhou et al. (2010) found that the use of two higher modes to the fundamental frequency could help to resolve ambiguities for damage detection in certain cases. Therefore the ability to measure and monitor higher modal frequencies using GPS would be of benefit to a Bridge Deformation Monitoring System. Identification of such frequencies in noisy data is difficult, and thus data cleaning is required.

Spectral analysis of 15 minutes worth of $20 \mathrm{~Hz}$ vertical deflection data from position $\mathrm{M}$ without filtering and then with filtering using a band-pass filter was carried out. The aim of the filtering was to remove noise in the GPS data, including low frequency effects such as multipath and temperature variation. This enabled better identification of any higher order frequencies present in the data. The 20 $\mathrm{Hz}$ vertical deflection data was passed through an IIR Butterworth band-pass filter with a pass band of $1 \mathrm{~Hz}$ to $8 \mathrm{~Hz}$. The $20 \mathrm{~Hz}$ sampling rate gives a Nyquist frequency of $10 \mathrm{~Hz}$ thus allowing frequencies of up

to $10 \mathrm{~Hz}$ to be identified. Again, the three main frequencies identified in the $10 \mathrm{~Hz}$ data were also identified in Figure 12 with a possible additional peak at $1.79 \mathrm{~Hz}$.

Figure 12: Amplitude spectrum of unfiltered $20 \mathrm{~Hz}$ vertical deflections 


\section{Viaduct Shape}

Using the average of all the data collected at each position along the outer rail of the viaduct on Day 2, the "shape" of a section of the viaduct was plotted in Figure 13. Because the graph uses straight lines to join the points, as well as the limited number of points, it is not an exact representation of the viaduct shape in that section however it does highlight an important issue which is that position A is higher than position $\mathrm{M}$ which is the midpoint and which would be expected to be the highest point. It should be noted that these points represent the antenna location located at the top of the handrail. However, this shape 'distortion' may be the cause of the water ponding effect observed on the bridge.

Figure 13: Viaduct profile on Day 2

Deflection and natural frequency results obtained from the trial were consistent with those predicted by an available FE model. Identification of any flat spots in the bridge profile is particularly important in the fatigue management of the structure. Previous work (Cunninghame et al., 1997) has shown that composite action of the steel and the mastic asphalt surfacing can reduce the stresses at welded joints by up to $90 \%$. However, the magnitude of the stress reduction is very dependent on the quality of bond between the surfacing and the steel deck, as localised water ponding can result in a breakdown of this bond due to pumping action caused by heavy vehicles.

\section{Weather Effects}

Environmental variations, such as varying temperature, moisture and wind speed will affect the dynamic response of structures such as the Avonmouth viaduct. These changes can often mask subtler structural changes caused by degradation or damage, and it therefore important to interpret the GPS deflection data

for the impact of environmental effects on the results. Weather data from various UK Highways Agency sites in the vicinity of the viaduct were obtained. The air temperature, and wind speed data measured at the site closest to the viaduct area on Day 2 are shown in Figure 14. The weather data was sampled on the hour and at 40 and 50 minutes past the hour. In order to compute a cross-correlation between the deflections and the temperature as well as the wind speed, the averaged deflection at mid-span from 10minute data blocks on Day 2 was used. The weather data in the period between the hour observation and 
the 40 minute observation was interpolated using a linear interpolation to obtain the values at 10 minutes intervals in between. The 10 minute average of the bridge deflections are shown in Figures 15 to 17.

Figure 14: Variation in air temperature and wind speed

Figure 15: 10 Minute average of lateral deflections at Midpoint on Day 2

Figure 16: 10 Minute average of longitudinal deflections at Midpoint on Day 2

Figure 17: 10 Minute average of vertical deflections at Midpoint on Day 2

The temperature, wind speed and deflection data for the time period of 7:40 to 15:00 were normalised into the same data range using the Min-Max normalisation (Equation 2).

$$
y^{\prime}=\left(\frac{y-\min 1}{\max 1-\min 1}\right)(\max 2-\min 2)+\min 2
$$

where min 1 and $\max 1$ are the original minimum and maximum, min 2 and max 2 are the new minimum and maximum. A cross correlation function was then computed between the vertical deflection and the air temperature, the vertical deflections and the wind speed and the longitudinal deflections and the air temperature. For the normalised cross correlation coefficient a value of zero indicates no correlation and 1 represents direct correlation.

Figure 18: Normalised cross correlation coefficient between air temperature and vertical deflection

The results in Figure 18 show a correlation coefficient of 0.69 between the air temperature and vertical deflections at zero lag while at lag $=15$ there is a maximum correlation of 0.84 . The time lag is in units of 10 minutes hence the time lag for maximum correlation is 150 minutes. There is a maximum cross correlation of 0.82 between the wind speed and vertical deflections at zero lag. There is another peak of 0.78 in the correlation coefficient at lag $=14$ which is equal to a time lag of 140 minutes. The results for the longitudinal deflections versus the air temperature show maximum correlation of 0.97 at zero lag (see Figure 19). This indicates that the mean movement of $\pm 10 \mathrm{~mm}$ visible in the longitudinal 
deflection data (Figures 14 and 15) is probably due to the effect of increasing temperature which causes expansion in the longitudinal direction with increased temperature.

Figure 19: Normalised cross correlation coefficient between air temperature and longitudinal deflection

Such an analysis of environmental effects can thus provide some correlation information which can be used in developing precise models for the environmental component of the structural response of the viaduct, and thus improving long term bridge deformation monitoring and damage detection. Ideally however, in order to perform more precise correlation between weather effects and deflections, a weather data sampling rate of 10 minutes is not adequate and a much higher sampling rate is required.

\section{CONCLUSIONS}

The results have shown that GPS is a viable deflection measurement tool for the relatively small deflections in a steel box girder viaduct which, unlike suspension and cable stayed bridges previously studied, has a much smaller range of deflections (in the range of some centimetres) and which the GPS sensor system was able to determine to the millimetre level. The results show that deflections can be measured at the millimetre level, with vertical displacement generally of about $+/-10 \mathrm{~mm}$. The major vertical frequency of $0.526 \mathrm{~Hz}$ has been identified along with higher order frequencies, while the dynamic profile of the structure (the primary aim of the survey) has also been measured. The good correlation of displaced form to wind and temperature mean that it is possible to calibrate measurements to environmental conditions and account for them.

All these quantities can be of significance to the engineer monitoring the structure. Advances in wireless technology enable all of these measurements to be taken remotely, whenever and at what time intervals structural engineers may require. The authors have advocated the use of this or similar technology on major critical infrastructure to establish a baseline for the as-built condition, so that any potential changes can be rapidly assessed.

Adequate numbers of satellites required for positioning were visible both on the viaduct and at the reference station sites, and while sites were affected to a limited degree by multipath, available multipath filtering techniques could be used to mitigate these. GPS receivers were able to detect the viaduct motion, and two main frequencies were clearly detected by the GPS in the vertical component. Further data filtering of $20 \mathrm{~Hz}$ data meant higher order (lower power) frequencies could also be 
identified. The two main frequencies were detectable at mid-span both on the outer rail (position $\mathrm{M}$ ) and on the inner rail (position D). However, looking at the raw position data from the inner rail there are sharp spikes in the plots of the data. This is likely to be as a result of momentary passage of high-sided vehicles causing interference in the GPS signal for just an instant. The inner rail may not be the best location for the GPS antenna.

\section{ACKNOWLEDGEMENTS}

We are pleased to acknowledge The Highways Agency for permission to publish this paper, and we would like to acknowledge the support of Balfour Beatty Mott MacDonald staff and in particular we gratefully acknowledge the help of Mr Bruce Pucknell in the preparation of this manuscript, and Mr Jon Phillips for his ongoing assistance on the project. We would like to thank Mr. Huib deLight of the IESSG for help in the data collection process, as well as Leica Geosystems for the loan of additional System 1200 GPS receivers. We would also like to acknowledge the assistance of the marine department of The Bristol Port Company in providing access to secure locations for the reference receivers.

\section{REFERENCES}

1. Ashkenazi, V., Dodson, A.H., Moore, T., and Roberts, G.W. (1996). Real Time OTF GPS Monitoring of the Humber Bridge, Surveying World, May/June 1996, Vol. 4, Issue 4, ISSN 0927-7900, pp 26-28.

2. Ashkenazi V. and G. W. Roberts (1997). Experimental Monitoring the Humber Bridge with GPS. In: Proc. Institution of Civil Engineers; Civil Engineering, Nov 1997, Vol. 120, Issue 4., pp. 177-182.

3. Atkins, C. (2006). Deflection Monitoring of the Forth Road Bridge and Wilford Footbridge using GNSS. MSc Thesis. Institute of Engineering Surveying and Space Geodesy (IESSG), University of Nottingham, September 2006.

4. BRIME (Bridge Management in Europe), http://www.trl.co.uk/brime. 
5. Brown, C. J., Karuna, R., Ashkenazi, V., Roberts, G. W. and R. Evans (1999) Monitoring of Structures using GPS, In: Proc Institution of Civil Engineers, Structures, February 1999, pp 97 105, ISSN 0965 092X.

6. Brownjohn J.M.W., (2005) Lateral loading and response for a tall building in the non-seismic doldrums; Engineering Structures, 27, pp. 1801-1812.

7. Celebi, M. and Sanli, A. (2002). GPS in Pioneering Dynamic Monitoring of Long-Period Structures, Earthquake Spectra, Journal of Earthquake Engineering Research Institute, Volume 18, No. 1, pages 47-61, February 2002.

8. Cunninghame, J. R., Barker, K. J. and Jacklin D., (1997) Avonmouth Bridge: Assessment of Composite Action Between Surfacing and Steel Deck. TRL Project Report PR/CE/36/97.

9. Cunha, A. and Caetano, E. (2006) Experimental Modal Analysis of Civil Engineering Structures, Sound and Vibration, Vol. 6, No. 40, pp.12-20, 2006.

10. Cunha, A., Caetano, E. and Magalhaes, F. (2007) - "Output-only Dynamic Testing of Bridges and Special Structures”, Structural Concrete, Journal of FIB, 8, No.2, pp.67-85, 2007

11. Doebling, S. W., Farrar, C. R., Prime, M. B., and Shevitz, D. W., (1996) Damage Identification and Health Monitoring of Structural and Mechanical Systems from Changes in their vibration Characteristics: a Literature Review. Tech. Rep. LA 13070-MS, Los Alamos National Laboratory, Los Alamos, NM, USA.

12. Farrar, C. R., Duffey, T. A., Doebling, S. W., Nix, D. A., (1999) A Statistical Pattern Recognition Paradigm for Vibration-Based Structural Health Monitoring. Presented at the 2nd International Workshop on Structural Health Monitoring Stanford, CA Sept 8-10, 1999.

13. Farrar, C. R., Doebling, S. W., and Nix, D. A., (2001) Vibration-based structural damage identification, Phil Trans R Soc Lond. 2001, 359, 131-149, doi: 10.1098/rsta.2000.0717

14. Farrar, C. R. and Worden, K., (2007). An Introduction to Structural Health Monitoring, Phil. Trans. R. Soc. A (2007) 365, 303-315, doi:10.1098/rsta.2006.1928.

15. Frangopol, D.M., Strauss, A., and Kim, S., (2008) Bridge Reliability Assessment Based on Monitoring, J. Bridge Engineering, ASCE, May/June 2008, pp 258-270. doi: 10.1061/(ASCE)1084-0702(2008)13:3 (258)

16. Hofmann-Wellenhof, B., Lichtenegger, H., and Collins, J., (2001) GPS Theory and Practice, (Fifth Edition), Springer-Verlag Wien, ISBN 978-3211835340.

17. Kashima, S., Yanaka, Y., Suzuki S., and Mori, K., (2001) Monitoring the Akashi Kaikyo Bridge: First Experiences, Structural Engineering International, Vol.11, No. 2, pp. 120-123(4) 
18. King, M. and Edwards, S., (2004) The Ups and Downs of GPS Heighting in Britain - part 2: The Troposphere. Engineering Surveying Showcase April 2004, pp. 30 - 32.

19. Leach M., Hyzak M., and Horoschak S., (1993) Validation and Analysis of Results from a Bridge Motion Monitoring Experiment, Proceedings 49th Annual Meeting "Future Global Navigation and Guidance" Cambridge, MA, USA, pp. 519-528

20. Leica, (2004) Leica GPS 1200 Series - GPS 1200 Technical Data. Leica Geosystems AG CH9435 Heerbrugg (Switzerland)

21. Leick A., GPS Satellite Surveying, 3rd Edition, John Wiley \& Sons, Inc, 2004

22. Lovse J.L., Teskey W.F., Lachepelle G., Cannon M.E. (1995) Dynamic deformation monitoring of tall structure using GPS technology. J Surv Eng 121(1):35-40

23. Lynch J.P. and Loh K.J., (2006) A Summary Review of Wireless Sensors and Sensor Networks for Structural Health Monitoring, The Shock and Vibration Digest, 38, 91

24. Meng, X. (2002) Real-time deformation monitoring of bridges using GPS/accelerometers. PhD thesis. The University of Nottingham, Nottingham, UK. 2002.

25. Nickitopoulou, A., Protopsalti, K., Stiros, S., (2006). Monitoring Dynamic And Quasi-Static Deformations of Large Flexible Engineering Structures With GPS: Accuracy, Limitations And Promises, Engineering Structures, 28(10), 1471-1482.

26. Ogaja C. and Satirapod C., (2007) Analysis of high-frequency multipath in 1-Hz GPS kinematic solutions, GPS Solutions, Volume 11, Number 4, 269-280

27. Ogundipe, O., and Roberts, G., (2011) Antenna Selection for Bridge Deformation Monitoring Comparison of Multipath Mitigation characteristics for Three Types of Antennas. In Proceedings of FIG Working Week 2011, Marrakech, Morocco, 18 - 22 May 2011.

28. Psimoulis, P., Pytharouli, S and STIROS, S., (2008a) Identification of Multiple Oscillation Frequencies with GPS, Based on Experimental Evidence and Analysis in The Frequency Domain. 13th FIG Symposium on Deformation Measurement and Analysis. LNEC, Lisbon, May $12-15,2008$.

29. Psimoulis, P., Stiros, S., (2008b). Experimental Assessment of the Accuracy of GPS and RTS for the Determination of the Parameters of Oscillation of Major Structures, Computer Aided Civil Infrastructure Engineering Vol 23, No.5, pp389-403

30. Roberts, G. W.; Brown, C. J.; Meng, X., (2006a) Bridge Deflection Monitoring; Tracking Millimeters Across the Firth of Forth. GPS World, February 2006, Vol 17 No 2, pp 26 - 31, ISSN 1048-5104. Questex Publications. 
31. Roberts, G. W., Meng, X., Brown, C. J. and Dallard, P., (2006b). GPS Measurements on the London Millennium Bridge. Proceedings- Institution of Civil Engineers Bridge Engineering, 159(4), pp 153-162.

32. Roberts G.W., Brown C.J., and Ogundipe, O (2010) Monitoring Bridges by GNSS, Paper 4452, XXIV FIG International Congress, Sydney, Australia, April 2010

33. Roberts G.W., Brown C.J., Meng X., Ogundipe O., Atkins C., and Colford B., (2011), 4-D Deflection Monitoring of the Forth Road Bridge by GPS., Proceedings Institution Of Civil Engineers Bridge Engineering, In Press, 2011.

34. Saeki M., (2008) Development of affordable GPS displacement monitoring system; in Bridge Maintenance, Safety Management, Health Monitoring and Informatics: Proceedings of the Fourth International Conference on Bridge Maintenance- IABMAS '08, Koh and Frangopol (Eds) July 13-17 2008, Seoul, Korea

35. Saeki, M., and Hori, M., (2006) Development of an Accurate Positioning System Using LowCost L1 GPS Receivers. Computer-Aided Civil and Infrastructure Engineering 21 (2006) 258267.

36. Salawu, O. S., (1997) Detection of Structural Damage Through Changes in Frequency: a Review. Engineering Structures, Vol. 19, No. 9, pp. 718-723, 1997.

37. Sohn, H., Farrar, C.R., Hemez, F. M., Shunk, D. D., Stinemates, D. W., Nadler, B. R., and Czarnecki, J., (2003) A Review of Structural Health Monitoring Literature: 1996-2001. Los Alamos National Lab Report LA-13976-MS, 2003.

38. Wang, R., Meng, X., Luo, L., Yao, L. and Huang, H., (2008). Statistic analysis of a prototype structural health monitoring system for the Nanpu Bridge in Shanghai, P. R. China. in Bridge Maintenance, Safety Management, Health Monitoring and Informatics: Proceedings of the Fourth International Conference on Bridge Maintenance- IABMAS '08, Koh and Frangopol (Eds) July 13-17 2008, Seoul, Korea

39. Xu, Y.L., Ko, J.M., and Yu, Z. (1997) 'Modal analysis of tower-cable system of Tsing Ma long suspension bridge', Engineering Structures, Vol.19, No.10, pp.857-867.

40. Yang, Y. B., and Chang, K.C., (2009) Extraction of Bridge Frequencies from the Dynamic Response of a Passing Vehicle Enhanced by the EMD Technique. Journal of Sound and Vibration 322 (2009) pp $718-739$. 
41. Yang, Y. B., Lin, C. W., Yau, J.D., (2004) Extracting bridge frequencies from the dynamic response of a passing vehicle. Journal of Sound and Vibration, Volume 272, Issues 3-5, 6 May 2004 pages $471-493$.

42. Zasso A, Vergani M, Bocciolone M, and Evans R,(1993) Use of a newly designed optometric instrument for long-term, long distance monitoring of structures, with an example of its application on the Humber Bridge, 2nd Intl Conf on Bridge Engineering, Univ. of Surrey, UK, 18-23 April 1993.

43. Zhou, Z., Wegner, L. D. and Sparling, B. F., (2010) Structural Health Monitoring of Precast Concrete Box Girders Using Selected Vibration-Based Damage Detection Methods. Advances in Civil Engineering Volume 2010, doi:10.1155/2010/280685. 


\section{Captions to Tables}

Table 1: Summary of results for the vertical deflections

Table 2: Summary of results for the lateral deflections

\section{Captions to Figures}

Figure 1a: Profile view of viaduct main river span

Figure 1b: Plan showing viaduct direction and GPS antenna locations

Figure 2: GPS antenna set up showing clamp and tribrach attachment

Figure 3: Vertical deflection of points along reference stations at the harbour and on the granary respectively profile on Day 2

Figure 4: Unfiltered vertical deflections of Midpoint receiver -2 minute extract

Figure 5: Deflections of Midpoint receiver on Day 1 from 14:30 - 17:00

Figure 6: Deflections of Midpoint receiver on Day 2 from 07:35 - 15:05

Figure 7: Amplitude spectrum for Midpoint 1 vertical deflection

Figure 8: Spectral analysis on the lateral deflections at Midpoint on Day 2

Figure 9: Spectral analysis on the longitudinal deflections at Midpoint on Day 2

Figure 10: Lateral torsional deflection on Day 2

Figure 11: Amplitude spectrum of lateral torsion deflection

Figure 12: Amplitude spectrum of unfiltered $20 \mathrm{~Hz}$ vertical deflections

Figure 13: Viaduct profile on Day 2

Figure 14: Variation in air temperature and wind speed

Figure 15: 10 Minute average of lateral deflections at Midpoint on Day 2

Figure 16: 10 Minute average of longitudinal deflections at Midpoint on Day 2

Figure 17: 10 Minute average of vertical deflections at Midpoint on Day 2

Figure 18: Normalised cross correlation coefficient between air temperature and vertical deflection

Figure 19: Normalised cross correlation coefficient between air temperature and longitudinal deflection 
VERTICAL CURVE RADIUS $9166.00 \mathrm{~m}$

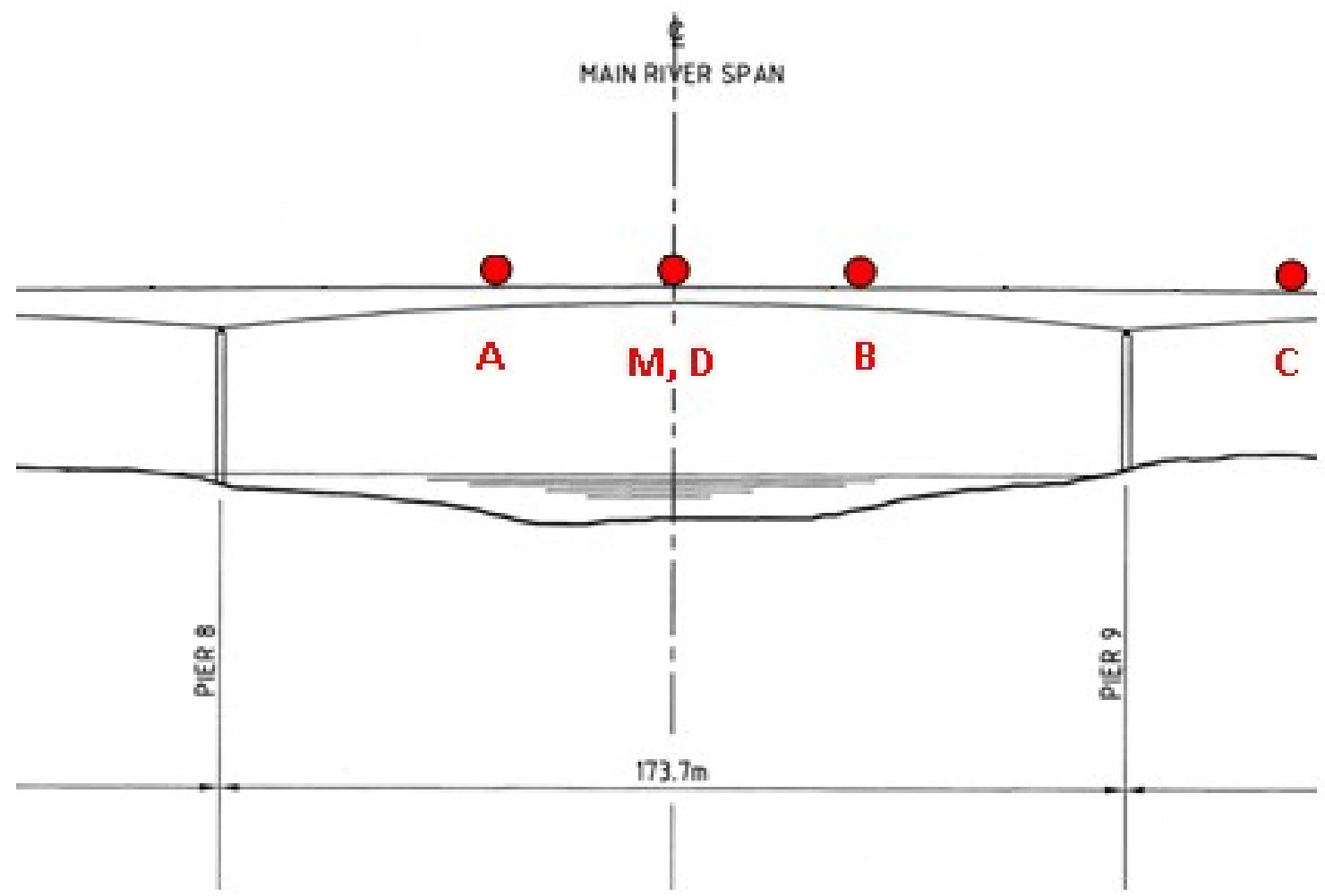




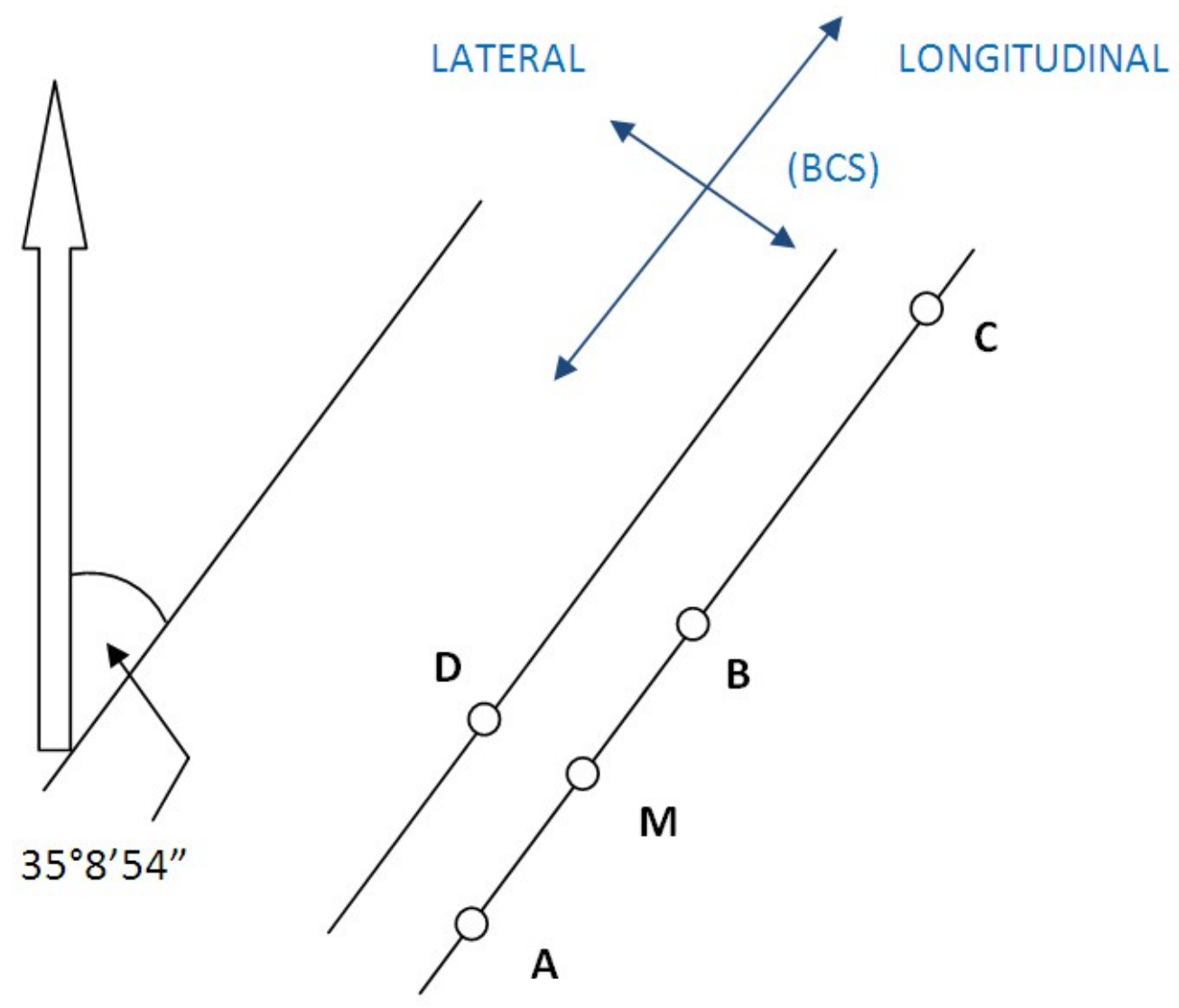



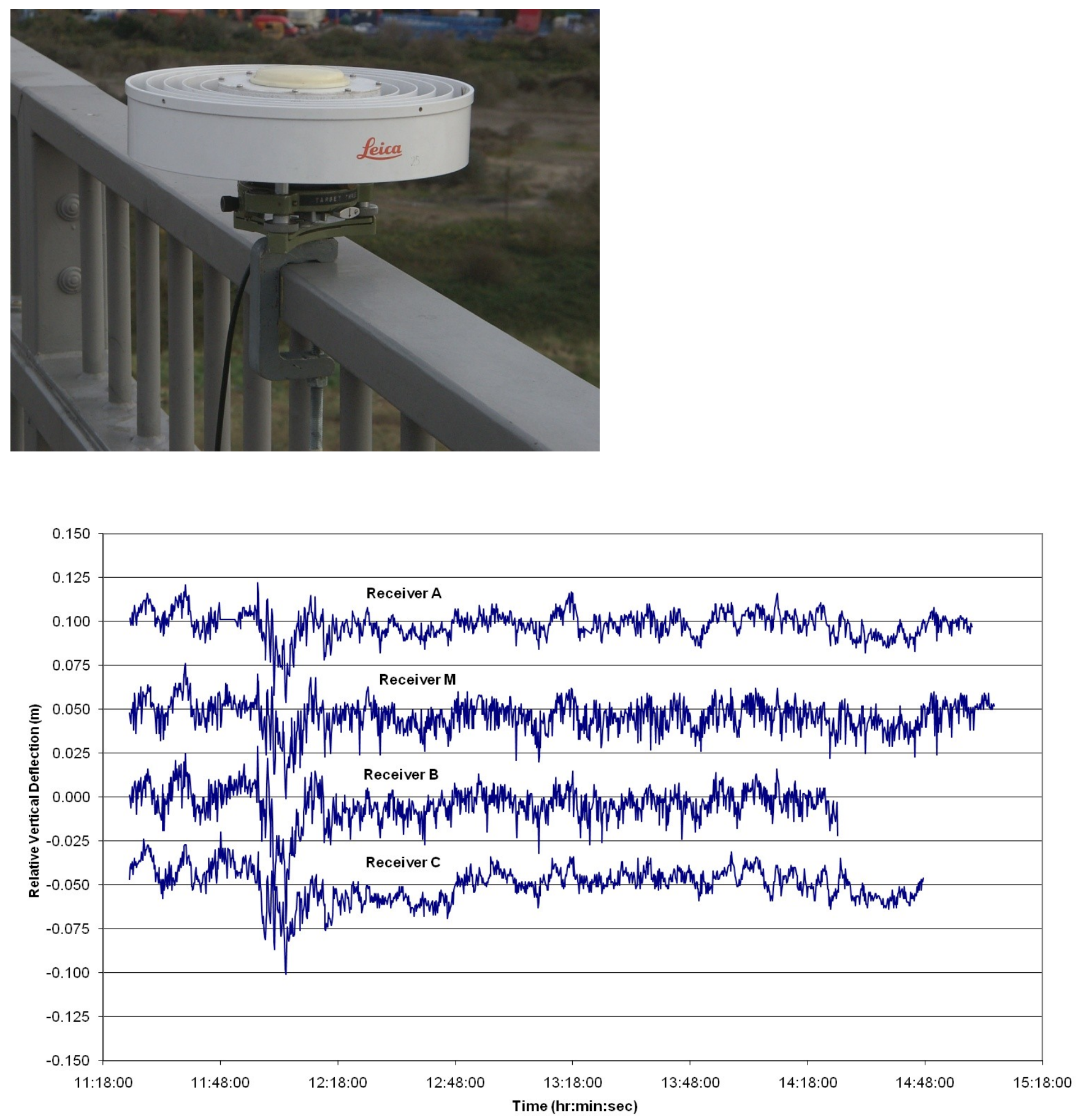

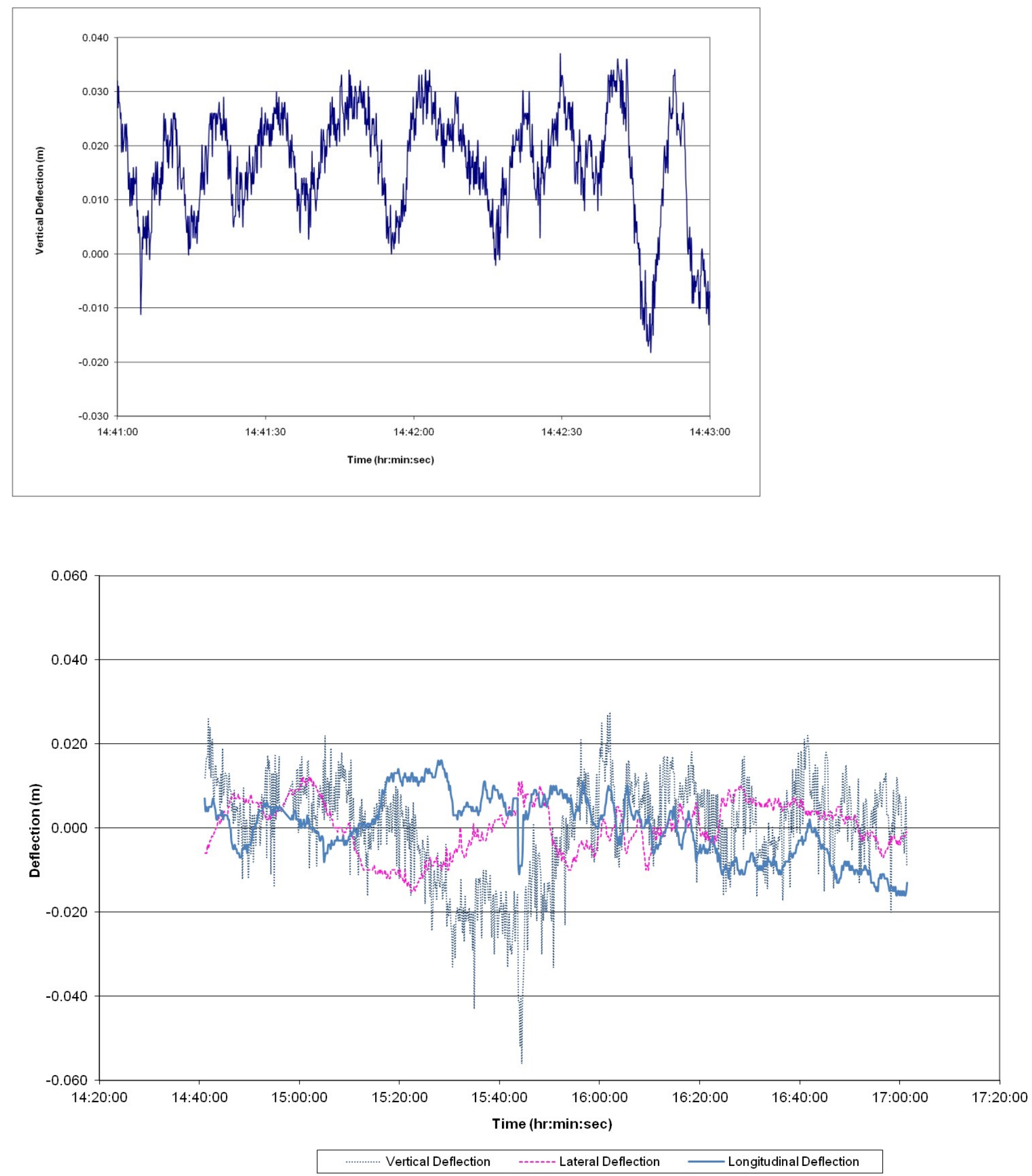

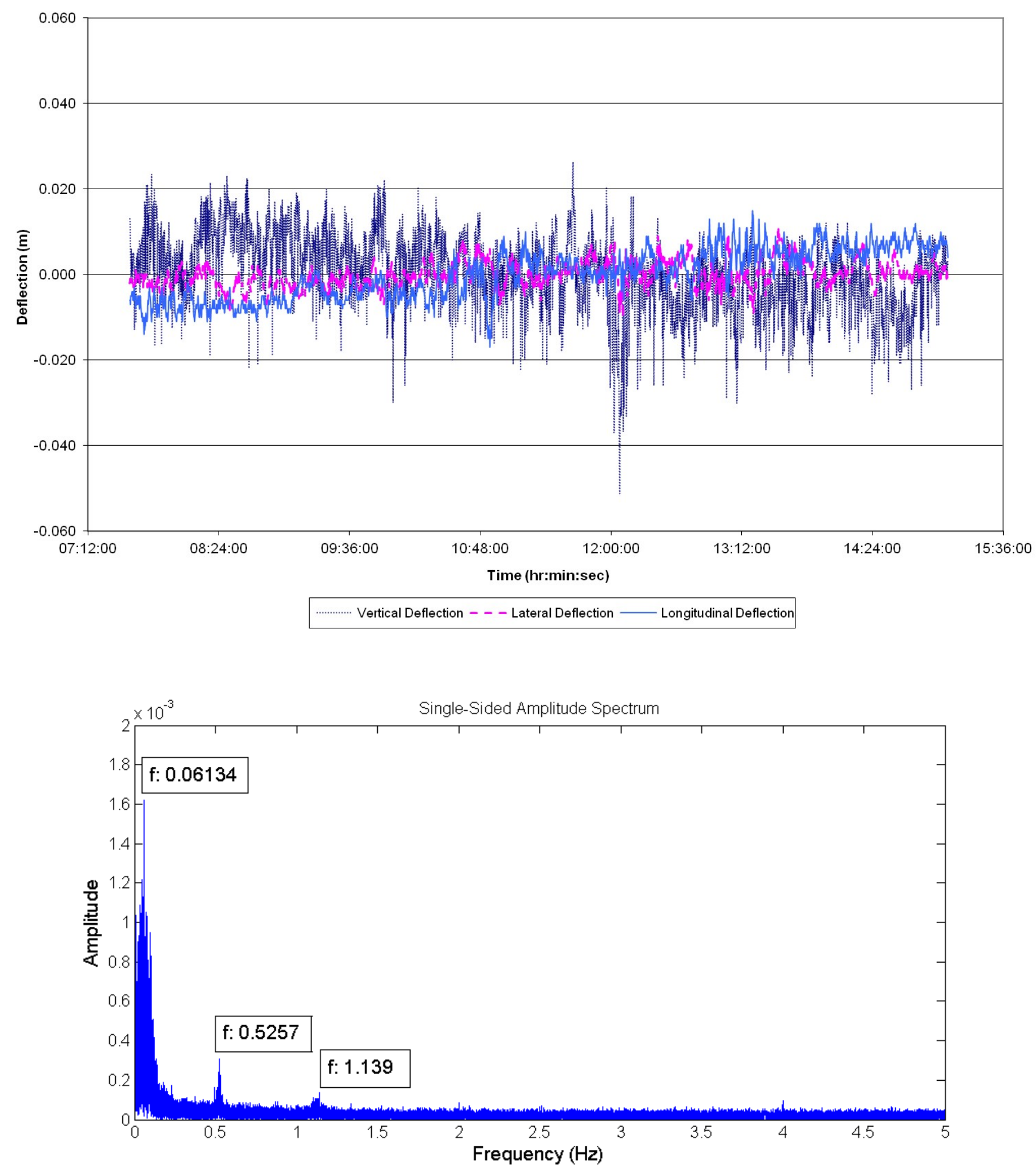

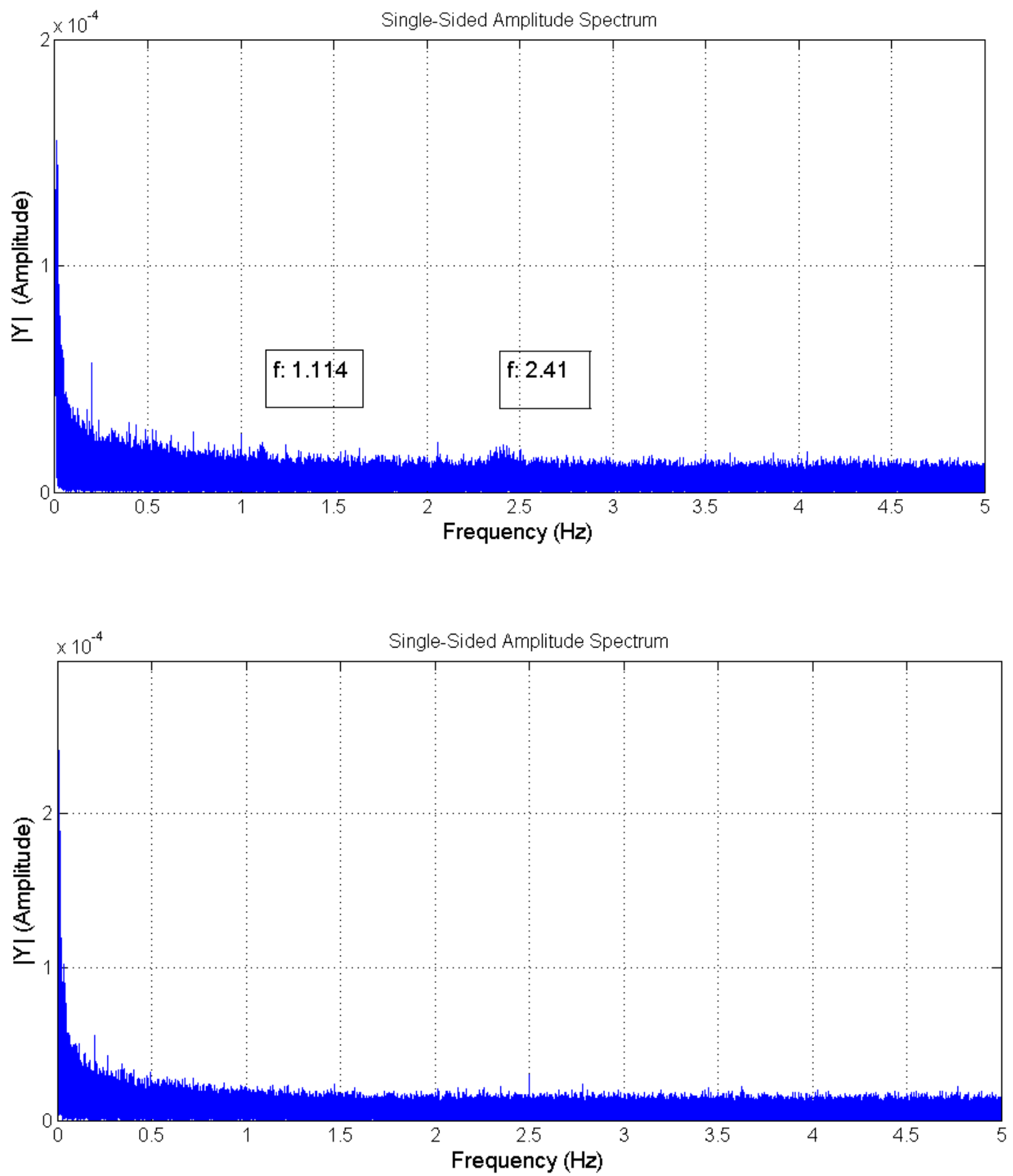

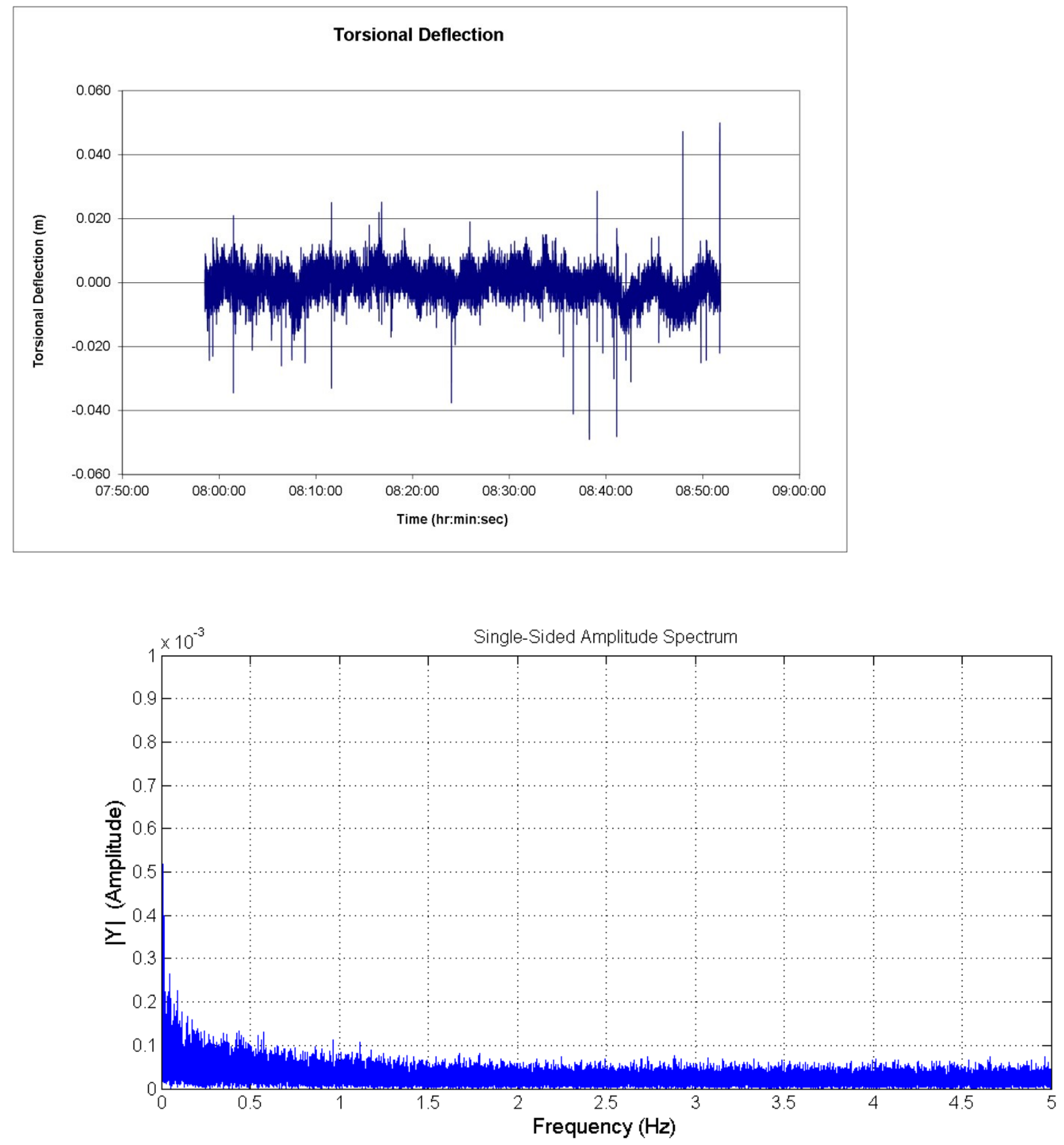

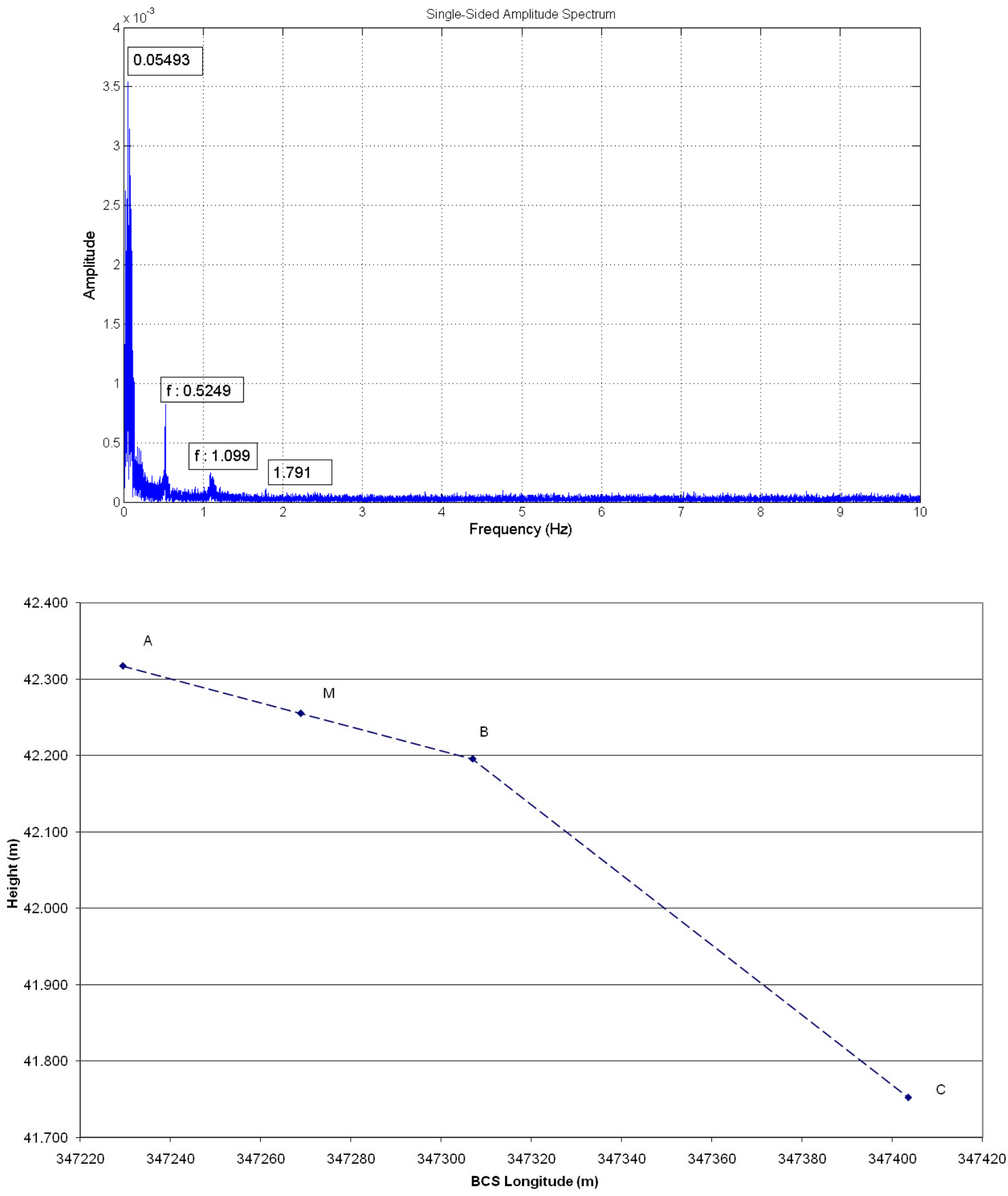

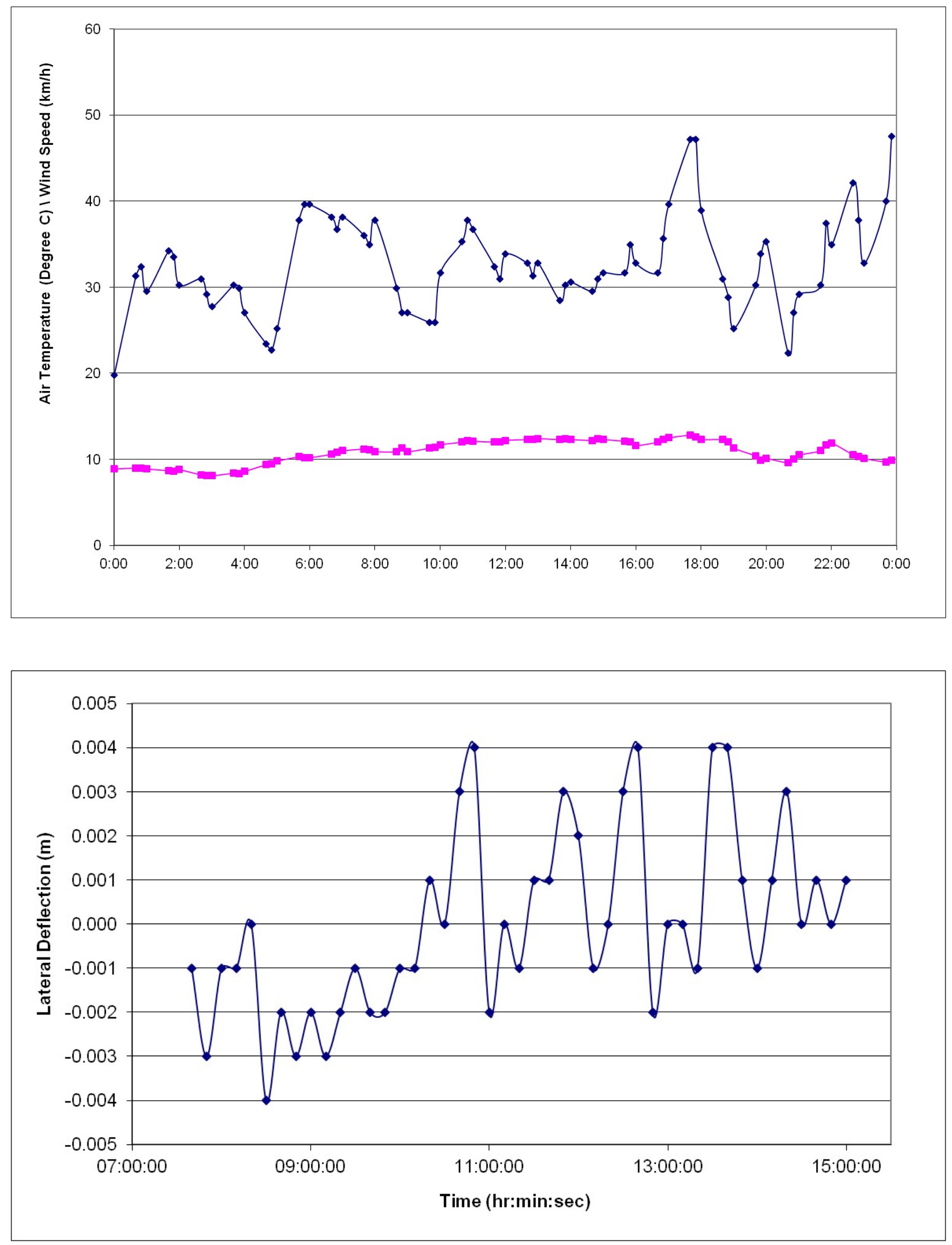


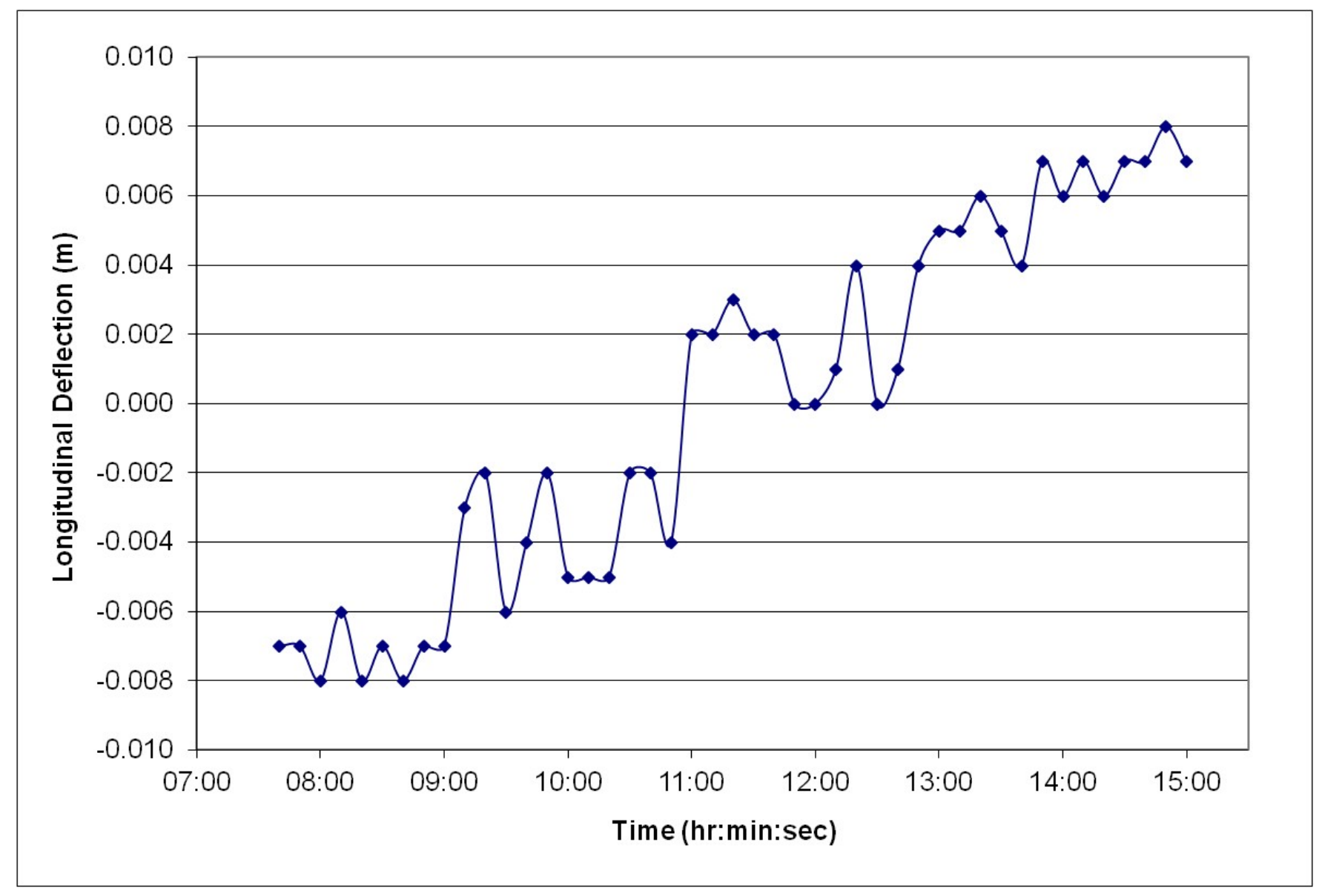



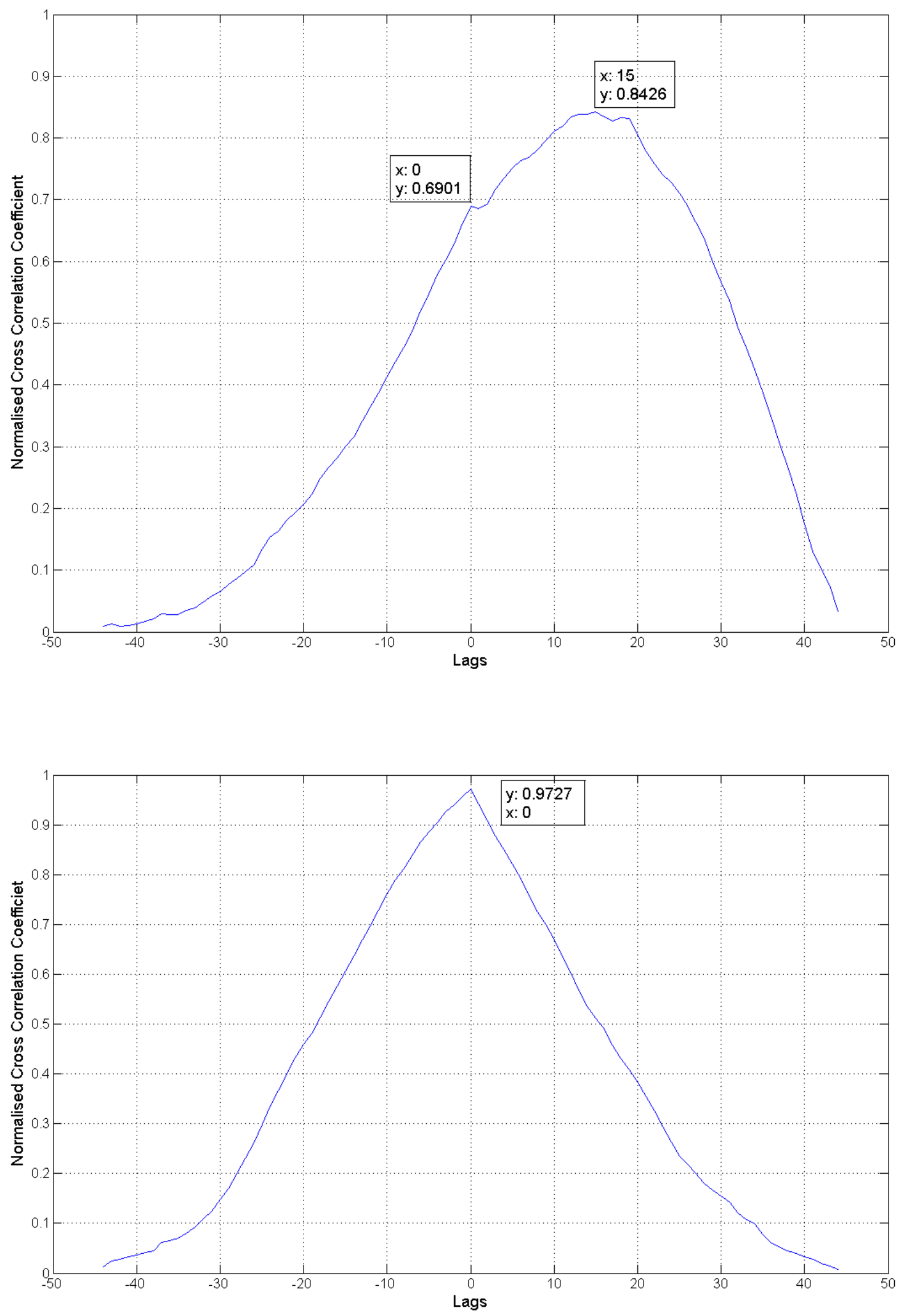


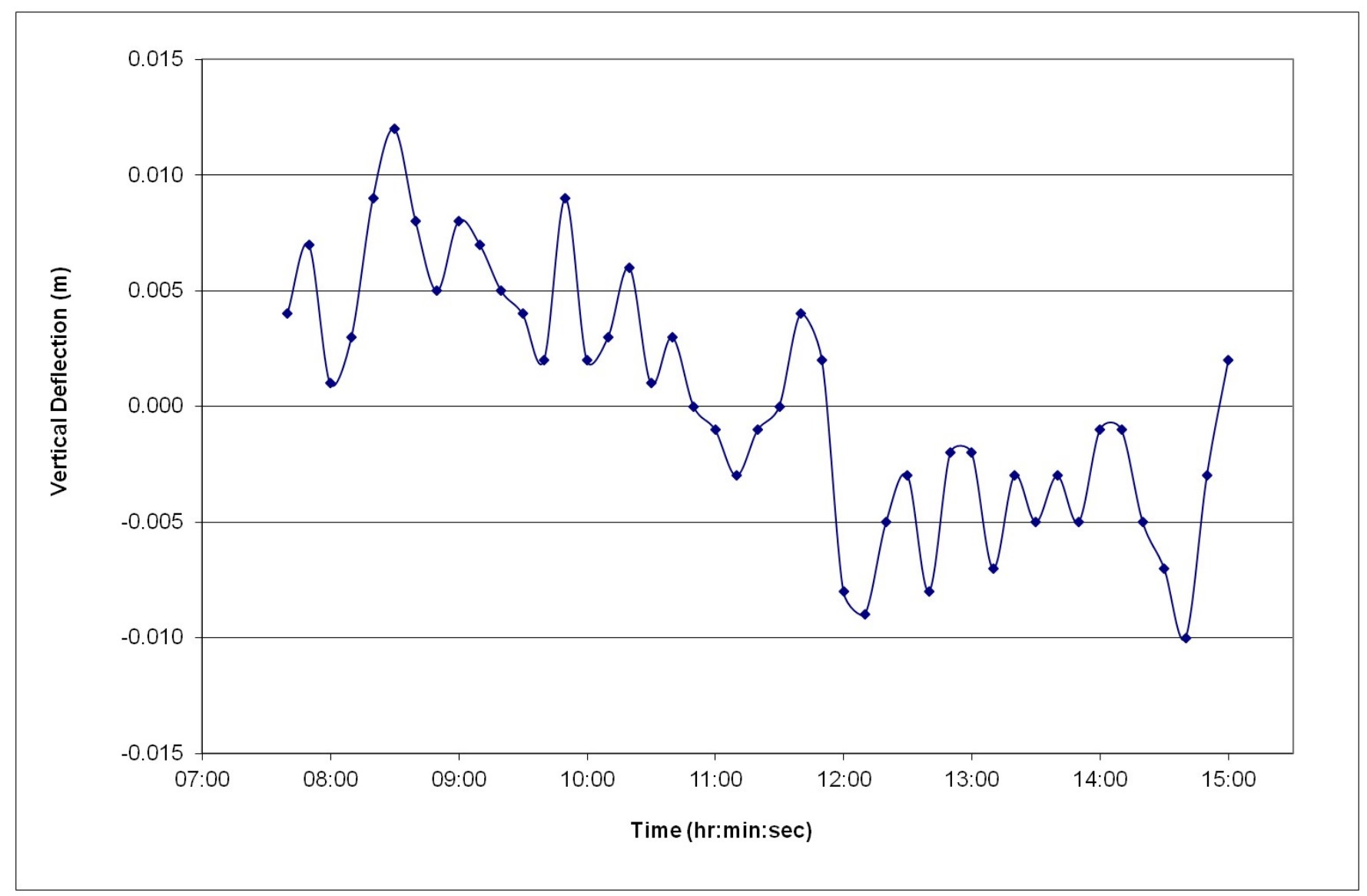




\begin{tabular}{|l|l|l|}
\hline & Day 1 & Day 2 \\
\hline Location & Frequency & Frequency \\
\hline A (right) & $0.06 ; 0.52 ; 1.10$ & $0.06 ; 0.52 ; 1.11$ \\
\hline M (midpoint) & $0.06 ; 0.53 ; 1.14$ & $0.07,0.09 ; 0.52 ; 1.11$ \\
\hline B (left) & $0.06 ; 0.53 ; 1.12$ & $0.09 ; 0.52 ; 1.10$ \\
\hline D (inner) & n/a & $0.06,0.09 ; 0.53 ; 1.12 ; 2.83$ \\
\hline
\end{tabular}

Table 1: Summary of results for the vertical deflections

\begin{tabular}{|c|c|c|}
\hline & Day 1 & Day 2 \\
\hline Location & Frequency & Frequency \\
\hline A (right) & $0.39 ; 1.12 ; 2.41$ & $\mathrm{n} / \mathrm{a}$ \\
\hline M (midpoint) & $0.34 ; 0.79,1.09 ; 2.37$ & $1.11 ; 2.41$ \\
\hline B (left) & 4.53 & $0.08 ; 1.11,1.50 ; 2.5$ \\
\hline D (inner) & $n \backslash a$ & \\
\hline
\end{tabular}

Table 2: Summary of results for the lateral deflections 